\title{
ergopraxis wird ein Jahr alt
}

_ Kaum zu glauben, habe ich gedacht, als ich diese Überschrift eingetippt habe. Das Jahr ging vorüber wie im Flug - interessant, turbulent, spannend. Zehn Ausgaben gibt es bisher von der ergopraxis. Ihre positiven Rückmeldungen bestärken uns, dass wir mit unserem Themenangebot auf dem richtigen Weg sind. Und dass Sie den frischen Wind, den wir Ihnen vor einem Jahr versprochen haben, gut finden. Dafür möchten wir uns bei Ihnen bedanken. Wir feiern Geburtstag und haben in dieser Ausgabe viele Geschenke für Sie (॰ Kasten „Zu gewinnen“). Machen Sie mit, es lohnt sich!

Herzlichst Ihre

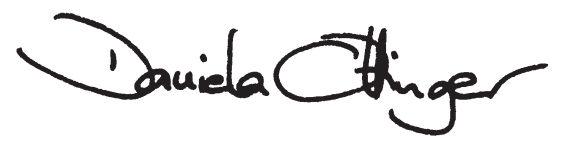

PS: Einen Geburtstagswunsch haben wir: Diesem Heft liegt ein Fragebogen bei. Bitte geben Sie uns Ihr Feedback! Damit wir mit ergopraxis im zweiten Lebensjahr noch besser Ihren Geschmack treffen. Außerdem können Sie mich persönlich unter daniela.ottinger@thieme.de erreichen.

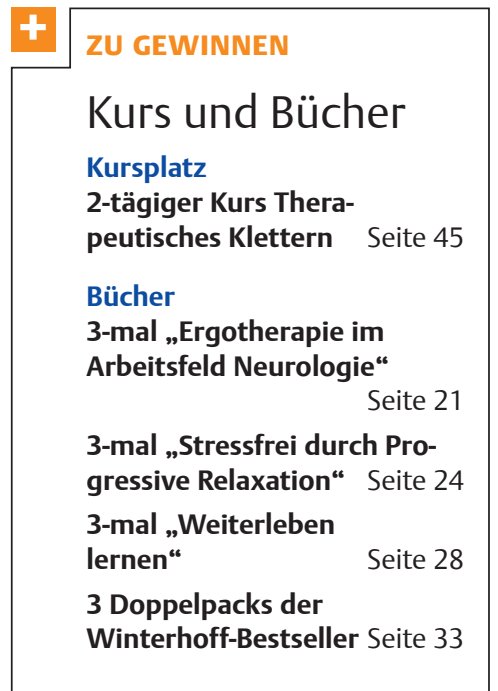

Das ergopraxis-Team (von links): Julia Belitz (Layout), Daniela Ottinger (inhaltliche Leitung), Annette Alkemade (Redaktion), Elke Baumann (Redaktionsleitung), Markus Böggemann (Marketing), Maria Czyganowski (Redaktion), Lioba Schlegel (Marketing), Simone Gritsch (Redaktion)

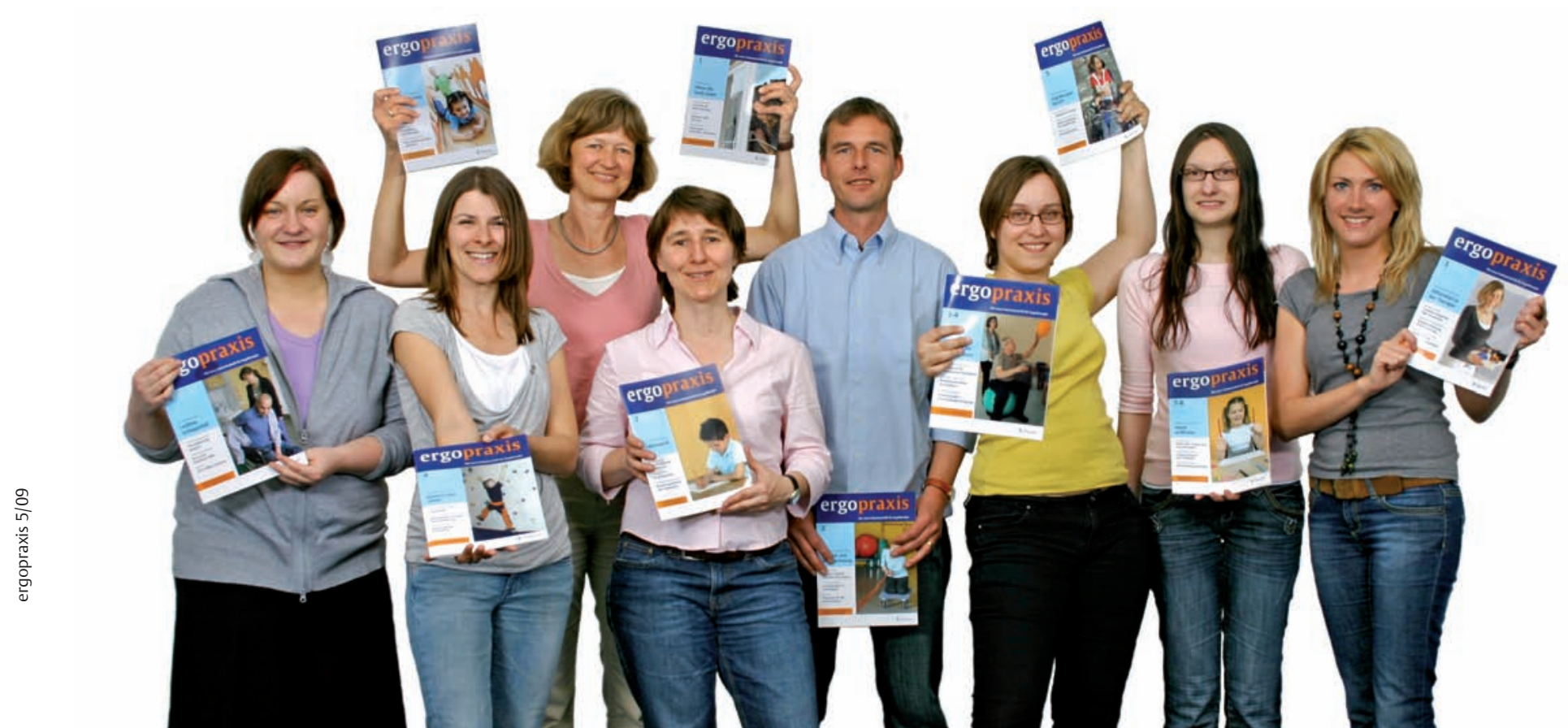

